\title{
BIOSYNTHESIS AND COMPOSITION OF STEROLS AND STEROL ESTERS IN THE LAND SNAIL CEPAEA \\ NEMORALIS (L.) (GASTROPODA, PULMONATA, STYLOMMATOPHORA)
}

\author{
D. J. VAN DER HORST and P. A. VOOGT \\ Laboratory of Chemical Animal Physiology, 40 Jan van Galenstraat, Utrecht, \\ The Netherlands
}

(Received 25 October 1971)

\begin{abstract}
The biosynthesis and composition of sterols and sterol esters were studied in the land snail Cepaea nemoralis after injection of $\mathrm{Na}-1-{ }^{14} \mathrm{C}$ acetate.

2. Free and esterified sterols appeared to be synthesized by the animals, whilst the specific radioactivity of the sterols from the esters was found to be higher than that of the free sterols after incubation for $48 \mathrm{hr}$.

3. The composition of sterols in both fractions was not significantly different.

4. The fatty acid moiety of the sterol esters appeared to be labeled as well and involved about sixty components, which are summarized from myristic acid onwards.
\end{abstract}

\section{INTRODUCTION}

IN ALL PHYLA of the animal kingdom the presence of sterols has been demonstrated. Apart from free sterols esterified ones have been reported from the protozoan Paramecium (Conner et al., 1971) up to mammalian brains (Eto \& Suzuki, 1971). In molluscs, the composition of sterols and the potential capacity of synthesizing sterols in various representatives have been fairly well documented (review: Voogt, 1972a). However, in all studies concerning molluscs sterols have been obtained after a saponification procedure, so no separation was made between free and esterified sterols. In previous studies on the lipids of the land snail Cepaea nemoralis (Gastropoda, Pulmonata, Stylommatophora) an active biosynthesis of fatty acids was observed, whilst the composition of the total fatty acids appeared to be rather complex (van der Horst, 1970); moreover, it was interesting whether this complexity would be continued in the fatty acid moiety of the sterol esters. Furthermore, on account of previous investigations of the biosynthesis and composition of total sterols of some stylommatophorans (Voogt, 1967, 1971a, 1972a) one would expect in Cepaea both an active biosynthesis and a complex composition of sterols, too. For these reasons $C$. nemoralis seemed to be a suitable animal to study the biosynthesis and composition of sterols and sterol esters. This paper deals with the results of this investigation. 


\section{MATERIALS AND METHODS}

Lipids of 350 snails of the species Cepaea nemoralis (L.) (Gastropoda, Pulmonata, Stylommatophora) (fresh weight $584 \mathrm{~g}$ ) were isolated after injection of each of the animals with $1 \mu \mathrm{c} \mathrm{Na}-1-{ }^{14} \mathrm{C}$-acetate as described elsewhere (van der Horst, 1970).

Phospholipids were removed from $1.8015 \mathrm{~g}$ of the total lipids by precipitating them in cold acetone (Lipsky et al., 1957). Eventually, remaining traces of phospholipids were separated from the neutral lipids by column chromatography on silicic acid (Mallinckrodt, 100 mesh) and Johns Manville Hyflo Super Cel $(2: 1, \mathrm{w} / \mathrm{w})$ (Hanahan et al., 1957). The neutral lipids made up only 29.4 per cent of the total lipid fraction, and $450 \mathrm{mg}$ were separated into lipid classes on Florisil (60-100 mesh) according to Carroll (1961). The sterol and sterol ester fractions were collected and their purity tested by TLC (Freeman \& West, 1966).

The sterol fraction appeared to be scarcely contaminated with other lipid components. Therefore, a further purification via the digitonides was omitted and sterols were directly obtained in a pure state by recrystallizing them from methanol. However, the sterol ester fraction $(65.4 \mathrm{mg}$ ) was heavily contaminated with yellow-coloured pigments, of which a part showed a deep-violet fluorescence after spraying thin-layer chromatograms with Rhodamine 6G and examining them under u.v. light.

This fraction was therefore further purified by preparative TLC on $0.5-\mathrm{mm}$ silica gel-G plates (solvent system according to Freeman \& West, 1966). Only $10 \mathrm{mg}$ of the fraction consisted of pure sterol esters, and these were saponified in $1.5 \mathrm{~N}$ alkaline methanol solution for $2 \mathrm{hr}$, after which sterols and fatty acids were obtained in the usual way (van der Horst, 1970; Voogt, 1971). Sterols were purified via the digitonides and recrystallized from methanol (Voogt, 1971), and $5.0 \mathrm{mg}$ of sterols were obtained in this way. For comparison, total sterols were isolated after saponification of another sample of the total lipids.

Sterols were analyzed as their trimethylsilyl derivatives by gas-liquid chromatography on the stationary phases SE-30 $(2 \%)$ and NPGS $(2 \%)$ as described elsewhere (Voogt, 1972b).

In addition, sterols were hydrogenated and acetylated to verify proportional composition according to carbon content. Sterols were identified by means of their steroid numbers calculated from the formulae:

$$
\begin{aligned}
\mathrm{SN} & =27+5.84 \frac{\log r r t_{\mathrm{B}}}{\log r r t_{\mathrm{cv}}} \quad(\mathrm{SE}-30), \\
\text { and } \mathrm{SN} & =27+8.63 \frac{\log r r t_{\mathrm{s}}}{\log r r t_{\mathrm{cv}}} \quad(\mathrm{NPGS})
\end{aligned}
$$

In these formulae SN stands for the steroid number of a sterol whilst $r r t_{\mathrm{s}}$ and $r r t_{\mathrm{cv}}$ stand for retention time (relative to cholestane) of this sterol and cholesteryl valerate, respectively.

The fatty acid fraction was methylated with diazomethane (Schlenk \& Gellerman, 1960) and purified by silicic acid column chromatography with hexane-diethylether $(95: 5, \mathrm{v} / \mathrm{v})$. Identification of the fatty acids was performed by a procedure which has been described in more detail in previous papers (van der Horst \& Voogt, 1969a, b; van der Horst, 1970) and involved separation of saturated and unsaturated fatty acids after preparing mercury adducts of the unsaturated ones, and gas-liquid chromatography of total, saturated and unsaturated samples. In addition, samples were hydrogenated. The instrument (Becker 1452) and the conditions of the two different columns used (20\% PEGA and 10\% Apiezon L) have been described previously (van der Horst, 1970).

Radioactivity of all lipid fractions was measured in toluene-Omnifluor (New England Nuclear) in a Packard instrument, Model 2420.

All organic solvents used in this study for TLC and column chromatography were of analytical grade and contained $10 \mathrm{ppm}$ BHT (2,6-di-tert butyl p-cresol) as an antioxidant. 


\section{RESULTS}

The various isolated lipid fractions and their radioactivities are summarized in Table 1.

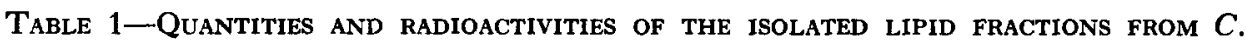
nemoralis

\begin{tabular}{|c|c|c|}
\hline Fraction & $\begin{array}{l}\text { Weight } \\
\text { (mg) }\end{array}$ & $\begin{array}{l}\text { Specific radioactivity } \\
(\mathrm{dpm} / \mathrm{mg})\end{array}$ \\
\hline Total lipids & & 2729 \\
\hline Neutral lipids* & 450 & 2135 \\
\hline Free sterols (crude) & $179 \cdot 6$ & $494 \cdot 0$ \\
\hline $\begin{array}{l}\text { Free sterols, after recrystallizing twice from } \\
\text { methanol }\end{array}$ & $172 \cdot 4$ & $360 \cdot 4$ \\
\hline $\begin{array}{l}\text { Free sterols, after recrystallizing three times } \\
\text { from methanol }\end{array}$ & & $361 \cdot 6$ \\
\hline Sterol esters (crude) & $65 \cdot 4$ & $3105 \cdot 5$ \\
\hline Sterol esters (purified) & $9 \cdot 7$ & $1309 \cdot 0$ \\
\hline $\begin{array}{l}\text { Sterols from sterol esters (pure) } \\
\text { Fatty acids from sterol esters (pure, as methyl } \\
\text { esters) }\end{array}$ & $\begin{array}{l}5 \cdot 0 \\
2 \cdot 6\end{array}$ & $\begin{array}{r}507 \cdot 8 \\
2620 \cdot 8\end{array}$ \\
\hline
\end{tabular}

* Neutral lipids stand for total lipids without phospholipids.

From the saponified total lipids sterols were obtained with a specific radioactivity of $342.6 \mathrm{dpm} / \mathrm{mg}$; this is somewhat lower than the sterols isolated by chromatography on Florisil. However, this difference in radioactivity does not seem to be significant.

The identification of sterols by means of steroid numbers is represented for free sterols in Table 2. The other fractions showed similar results.

TABLE 2-STERoId NUMBERS (SN) OF THE FREE STERols FROM $C$. nemoralis AND THE CALCULATED STEROID NUMBERS OF THE SUITABLE STEROLS, DETERMINED FOR TWO STATIONARY PHASES

\begin{tabular}{llc}
\hline \multicolumn{1}{c}{ Component } & SN (SE-30) & SN (NPGS) \\
\hline 1. & $30 \cdot 20$ & $30 \cdot 38$ \\
Cholesterol & $30 \cdot 18$ & 30.36 \\
2. & 30.58 & $30 \cdot 82$ \\
Brassicasterol & 30.58 & 30.83 \\
3. & 31.17 & 31.43 \\
Campesterol & 31.19 & 31.43 \\
4. (?) & $31.53($ ?) & \\
Stigmasterol & 31.50 & \\
5. & 32.05 & 32.27 \\
$\beta$-Sitosterol & 32.04 & 32.29 \\
\hline
\end{tabular}


D. J. van der Horst and P. A. Voogt

Proportional composition of all fractions is summarized in Table 3. As is seen from this Table, no remarkable differences could be observed between the sterol compositions of the three fractions.

Table 3-Proportional composition of the three Sterol fractions From $C$. nemoralis, AS DETERMINED ON TWO STATIONARY PHASES

\begin{tabular}{lccc}
\hline \multicolumn{1}{c}{ Sterol } & $\begin{array}{c}\text { Free sterols } \\
(\%)\end{array}$ & $\begin{array}{c}\text { Sterol esters } \\
(\%)\end{array}$ & $\begin{array}{c}\text { Total sterols } \\
(\%)\end{array}$ \\
\hline Cholesterol & $92 \cdot 0$ & $92 \cdot 5$ & $93 \cdot 1$ \\
Brassicasterol & $2 \cdot 1$ & $1 \cdot 8$ & $1 \cdot 5$ \\
Campesterol & $2 \cdot 9$ & $2 \cdot 5$ & $2 \cdot 8$ \\
Stigmasterol (?) & Trace (?) & $2 \cdot 8$ & $2 \cdot 6$ \\
$\beta$-Sitosterol & $2 \cdot 7$ & $2 \cdot 8$ & 2 \\
\hline
\end{tabular}

The fatty acid moiety of the sterol esters involved about sixty components, which are summarized in Table 4 from myristic acid (14:0) onwards.

TABle 4 - Composition (in mole per cent) OF THE FATTY ACIDS OF THE STEROL ESTERS FROM C. nemoralis, AS DETERMINED ON TWO STATIONARY PHASES

\begin{tabular}{|c|c|c|c|c|c|}
\hline Fatty acid & $\%$ & $\begin{array}{c}\text { Percentage } \\
\text { after } \\
\text { hydrogenation }\end{array}$ & Fatty acid & $\%$ & $\begin{array}{c}\text { Percentage } \\
\text { after } \\
\text { hydrogenation }\end{array}$ \\
\hline $14: 0$ & $0 \cdot 45$ & 0.95 & $20: 0$ & 0.72 & $29 \cdot 75$ \\
\hline $14: 1$ & 0.50 & - & $20: 1$ & 4.42 & - \\
\hline $15: 0 \mathrm{br}^{*}$ & 0.80 & & $20: 2$ & 11.46 & — \\
\hline $15: 0$ & 0.70 & $1 \cdot 12$ & $20: 3$ & $3 \cdot 43$ & - \\
\hline $15: 1$ & 0.42 & - & $20: 4(\omega 6)$ & $9 \cdot 41$ & - \\
\hline $16: 0 \mathrm{br}$ & 0.82 & & $20: 4(\omega 3)$ & $0 \cdot 31$ & 一 \\
\hline $16: 0$ & $9 \cdot 52$ & $10 \cdot 62$ & $21: 0 \mathrm{br}$ & $1 \cdot 42$ & \\
\hline $16: 1$ & $1 \cdot 10$ & - & $21: 0$ anteiso & 0.50 & \\
\hline $17: 0 \mathrm{br}$ & 0.56 & & $22: 0 \mathrm{br}$ & $1 \cdot 37$ & \\
\hline $17: 0$ anteiso & $3 \cdot 55$ & & $22: 0$ & $1 \cdot 16$ & $11 \cdot 92$ \\
\hline $17: 0$ & 1.04 & 1.54 & $22: 1$ & $1 \cdot 50$ & $\ldots$ \\
\hline $17: 1$ & $0 \cdot 50$ & - & $22: 3$ & $3 \cdot 71$ & - \\
\hline $18: 0 \mathrm{br}$ & 0.42 & & $22: 4$ & $5 \cdot 17$ & - \\
\hline $18: 0$ & $9 \cdot 66$ & $23 \cdot 54$ & $22: 5$ & $0 \cdot 38$ & $\ldots$ \\
\hline $18: 1$ & $5 \cdot 32$ & - & $23: 0 \mathrm{br}$ & 0.92 & \\
\hline $18: 2$ & $7 \cdot 02$ & - & $24: 0 \mathrm{br}$ & 0.98 & \\
\hline $18: 3$ & $1 \cdot 54$ & 一 & $24: 0$ & 0.08 & 0.96 \\
\hline 19:0 br & 0.72 & & $24: 1$ & $0 \cdot 88$ & - \\
\hline $19: 0$ anteiso & $0 \cdot 54$ & & 25:0 anteiso & $1 \cdot 23$ & \\
\hline $19: 0$ & 0.51 & 0.89 & $25: 0$ & $2 \cdot 38$ & - \\
\hline $19: 1$ & 0.38 & - & $27: 0 \mathrm{br}$ & $2 \cdot 58$ & \\
\hline
\end{tabular}

${ }^{*} \mathrm{br}=$ branched, as discussed in the text. 


\section{DISCUSSION}

From the data concerning radioactivities of the lipid fractions (Table 1) it is clear that $C$. nemoralis is capable of synthesizing not only free sterols, but esterified ones as well. In general, sterol synthesis of this snail is consistent with the view that all herbivorous pulmonates are capable of sterol synthesis (Voogt, 1968). Nevertheless, it is remarkable that an animal with an overwhelming predominance of $\mathrm{C}_{27}$-sterols like Cepaea is synthesizing sterols on such a high level, considering the fact that most sterols in the diet (plants) are $\mathrm{C}_{28}$ or $\mathrm{C}_{29}$ sterols. For instance, when Cepaea was kept in the laboratory on a diet of green lettuce for a period varying from several days to several weeks and the sterols of this diet were analyzed in order to study their influence on the sterol composition of $C$. nemoralis, $\mathrm{C}_{29}$ sterols appeared to be the major ones (stigmasterol 31.12 per cent; $\beta$-sitosterol 46.41 per cent). In Cepaea, $\beta$-sitosterol is at about 2.7 per cent, whilst stigmasterol has been detected only in a trace amount (Table 3 ). Therefore, one would expect a modification (dealkylation) of phytosterols in these animals instead of the use of the injected acetate for sterol synthesis. A possible explanation of this metabolic behaviour is that the content of sterols in plants is perhaps too low to meet the needs of $C$. nemoralis, in which sterols are indeed one of the major lipid classes (nearly half of the neutral lipids).

The composition of free and esterified sterols scarcely appeared to be different (Table 3), especially if the difficulty in calculating the exact percentages of the minor components is taken into account.

In a review on the metabolism of cholesterol esters Goodman (1965) has suggested several functions for these esters, viz; first, a role in the transport of sterols, second, a chemically more stable form in which to store sterols and, third, esterification of sterols could provide protection against oxidation of the reactive $3 \beta$ hydroxyl group of the sterols during modification of other parts of the sterol molecules. The role of sterol esters in invertebrates is still unknown, but it may be possible that they fulfil in Cepaea some of the functions suggested above. The transport of newly synthesized sterols as sterol esters could be an explanation for the higher specific radioactivity in the sterol part of the esters than in the free sterols.

The fatty acid composition of the esters is complex and comparable with the total fatty acids. An iso-type of branching could not be detected in these fatty acids, but equally the presence of iso-branched fatty acids could not be demonstrated in the total lipids. The type of branching indicated as "br" in Table 4 is not yet certain, IR and NMR studies of branched-chain fatty acid fractions suggest a methyl branching somewhere else in the aliphatic chains (van der Horst, to be published). In sterol esters of mammalian tissues, emphasis is laid on polyunsaturated fatty acids esterified to the sterol moiety (Goodman, 1965). It is remarkable that in Cepaea the content of these fatty acids in the sterol esters is lower than in the total fatty acids, with the exception of $\mathrm{C}_{22}$ acids. The specific radioactivity of the sterol ester fatty acids is high $(2620.8 \mathrm{dpm} / \mathrm{mg})$, but the 
radioactivity of the fatty acids possibly related to sterol ester biosynthesis (phospholipids) is much higher $(4514.7 \mathrm{dpm} / \mathrm{mg}$; van der Horst, to be published). Both the function and biosynthesis of sterol esters in these molluscs must be studied in more detail, especially because the high incorporation of ${ }^{14} \mathrm{C}$ in these components indicates their significance in the lipid metabolism of the snails.

\section{REFERENCES}

Conner R. L., Landrey J. R., Kaneshiro E. S. \& van Wagtendonk W. J. (1971) The metabolism of stigmasterol and cholesterol by Paramecium aurelia. Biochim. biophys. Acta 239, 312-319.

Carroll K. K. (1961) Separation of lipid classes by chromatography on florisil. 7. Lipid Res. 2, 135-141.

Eтo Y. \& Suzukı K. (1971) Cholesterol ester metabolism in the brain: properties and subcellular distribution of cholesterol-esterifying enzymes and cholesterol ester hydrolases in adult rat brain. Biochim. biophys. Acta 239, 293-311.

Freeman C. P. \& West D. (1966) Complete separation of lipid classes on a single thin layer plate. F. Lipid Res. 7, 324-327.

Goodman D. S. (1965) Cholesterol ester metabolism. Physiol. Rev. 45, 747-839.

Hanakan D. J., Dittmer J. C. \& Warashina E. (1957) A column chromatographic separation of classes of phospholipids. \%. biol. Chem. 228, 685-700.

Lipsky S. R., HaAvik A., Hopper C. L. \& McDivitT R. W. (1957) The biosynthesis of fatty acids of the plasma of man-I. \%. Clin. Invest. 36, 233-244.

SCHLENK H. \& Gellerman J. (1960) Esterification of fatty acids with diazomethane on a small scale. Analyt. Chem. 32, 1412-1414.

VAN DER HORST D. J. (1970) Investigation of the synthesis and distribution of fatty acids in the lipids of the snail Cepaea nemoralis (L.)- $-\mathrm{I}$. The fatty acid composition of the total lipids. Neth. F. Zool. 20, 433-444.

VAN DER Horst D. J. \& VOOGT P. A. (1969a) Investigation of the fatty acid composition of the snail Arianta arbustorum. Archs int. Physiol. Biochim. 77, 507-514.

VAN DER HORST D. J. \& VOOGT P. A. (1969b) Investigation of the fatty acid composition of the snail Succinea putris L. Comp. Biochem. Physiol. 31, 763-769.

Voogt P. A. (1967) Biosynthesis of $3 \beta$-sterols in a snail, Arion rufus L., from $1{ }^{14} \mathrm{C}$-acetate. Archs int. Physiol. Biochim. 75, 492-500.

Voogt P. A. (1968) Investigation of the capacity of synthesizing $3 \beta$-sterols in Mollusca-II. Study on the biosynthesis of $3 \beta$-sterols in some representatives of the order Basommatophora. Comp. Biochem. Physiol. 25, 943-948.

Voogt P. A. (1971) Sterol biosynthesis. Exp. Physiol. Biochem. 4, 1-33.

Voogt P. A. (1972a) Lipid and sterol components and metabolism in molluscs. In Chemical Zoology (Edited by Florkin M. \& Scheer B. T.), Vol. VII, Ch. IX. Academic Press, London, New York.

Voogt P. A. (1972b) The biosynthesis and composition of $3 \beta$-sterols in the neogastropods Purpura lapillus and Murex brandaris. Comp. Biochem. Physiol. 41B, 831-841.

Key Word Index-Cepaea nemoralis; sterols; sterol esters; fatty acids; pulmonates; sterol metabolism in a snail; fatty acid metabolism in a snail; lipids. 